\title{
Analysis on the Share Price and Forecasting Calculation Data of Activision Blizzard, Inc. Based on SWOT-Model
}

\author{
Jiahao Zhang \\ Nankai University, Tianjin, 300071, China
}

\begin{abstract}
In recent years, increasingly advanced technology infrastructure leads to an extraordinary growth of Internet users. By virtue of the explosive growth of the entire Internet industry, the online game industry has shown a rapid development trend, and the overall user scale of online games continues to expand. Meanwhile, the online game industry becomes a good investment market for investors to operate in. This article uses Blizzard as an example to analyze its investment value. Besides, the future trend of the video game industry is analyzed by using the SWOT-model and forecasting calculation data. The result shows that based on the current development of the game industry environment and the same companies in the game industry, Activision Blizzard will have a steady increase in profits in the future. Therefore, it is worth being invested.
\end{abstract}

\section{INTRODUCITON}

Recently, the development of video games has entered a period of sophistication. Online game platforms and the quality of games have been constantly improved with the global development of the Internet, and upgrading of computers, smart-phones, tablets as well as other electronic devices. The global game market experienced a sharp increase in the past decades. According to a report released by Newzoo in 2018, the global gaming market reached $\$ 137.9$ billion, up to $\$ 16.2$ billion from the previous year, and will continually increase to reach $\$ 180.1$ billion by 2021[1]. Meanwhile, the Asia-pacific region will continue to be the fastest-growing region, contributing \$24.9 billion, which accounts for 59 percent of the total $\$ 42.2$ billion growth in the global gaming market over the next three years. By 2007, it had taken more than 35 years for the global gaming market to grow to $\$ 35$ billion. However, in 2018 , the market generated $\$ 137.9$ billion in revenue, increasing about $\$ 100$ billion in just 11 years, from 2007 to 2018[2].

The statistical figures provided by Newzoo indicate a great performance accomplished by the game market in the past years and its great possibility to boom in the future. However, the boom of the Internet and software industries may have a short life cycle and make a bubble. The consequent result of this can lead to a great loss to the company. In this respect, it is difficult to tell the pros and cons of investing capital in the video game industry. This study uses Activision Blizzard as an example to analyze the benefit of investing video game and the development trend of the video game industry.

\section{ANALYSIS ON THE INDUSTRY}

The history of the video game industry starts from the middle of the last century to the present days. The three major video game industries - console games, PC games, and mobile games - have experienced newborn, developing, and sophisticated stages. Nowadays, the segmented chain of the game industry is matured. For example, in the case of the American video game industry, the market has already entered into a stable and complete status.

\subsection{Industry Status}

In 2019, the global gaming market will reach $\$ 150$ billion, up 8.7 percent from 2018 , according to Newzoo. From the perspective of regional distribution, the Asia-pacific region is still the growth engine of the global game market. In 2019, the size of the game market in the Asia-pacific region will reach 71.4 billion US dollars, accounting for $51.8 \%$ of the global market, with a year-on-year growth of $16.8 \%$. In North America, the market size is about 32.7 billion, accounting for $23.7 \%$, with a year-on-year growth of $10.0 \%$. Latin America was second only to the Asia-pacific region in terms of market size growth, at 13.5 percent. Among them, China has the largest mobile game market in the world, which reached 19.44 billion in 2019 , accounting for $30.8 \%$ of the total figure of the global market. In the United States, the market size is about 11.27 billion, accounting for $17.8 \%$. Japan ranks third with market size of $\$ 11.06$ billion, accounting for $17.5 \%[3]$. 


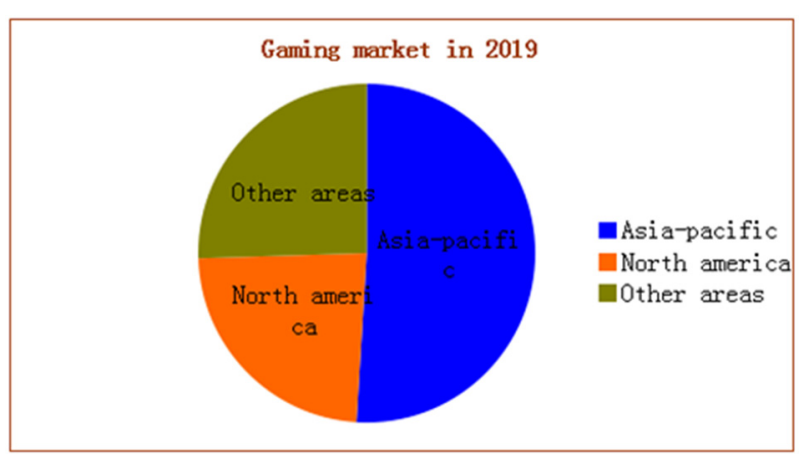

Figure 1. Gaming market in 2019.

\subsection{Industry development history and development trend}

As the birthplace of the video games, the United States forms the earliest video game market in the world. In the early days of the market, Atari, the founder of video games, lead the trend of the world. The Atari shock in 1983 had a considerable impact on the U.S market. The United States lost its position as the game industry leader to Japan during the period of the 1980s. Since then, the huge achievement of Microsoft and Blizzard facilitates the American game market to enter a period of rapid growth once again. The United States has been the global leader in several aspects for an extended period, which including game content development, game hardware development, e-sports promotion, and market user accumulation.

Driven by the emerging game markets, such as India and other countries of the Asia-pacific region, the mobile gaming industry saw another surge in revenues in 2019. However, due to the further improvement of the regulatory system, the newly released game may reduce its development potential in the future game market of China. In the meanwhile, the regulatory system of the Chinese market became stricter than before, and the establishment of a committee on game ethics will increase the difficulty for overseas publishers to distribute games in China. Overseas companies have to invest more time energy and resources to optimize their products and services to meet the standards of the game ethics committee. As a result, merely overseas companies that have sufficient financial resources and advanced products will attempt to release games in China. The new rules will also allow Chinese game companies to focus on overseas markets, especially those market with huge potential in Southeast Asia, Japan, South Korea, Europe, the United States, and the Middle East.

\subsection{Company profile}

Activision Blizzard (nasdaq: ATVI) is a U.S. game developer, publisher and distributor that was renamed in 2008 after the merger of U.S. video game publisher Activision, inc. with Vivendi games. Activision Blizzard is currently the world's largest game developer and publisher.

Activision Blizzard's main business continues Activision's model. Many Chinese players know Activision from the merger of Activision and Vivendi games, a subsidiary of Vivendi group. In fact, Activision was the world's second-largest third-party video publisher after EA before its merger with Vivendi games, which produced such titles as the call of duty series and guitar hero series.

Vivendi games' business had been unable to meet the requirements of French giant Vivendi sa before the merger. Vivendi games is a subsidiary of Vivendi group, which reorganized its gaming business. It has divisions such as Sierra entertainment and Blizzard entertainment, which are responsible for their respective businesses. But Sierra's business has shrunk over the years, and Blizzard itself is a better-known subsidiary. On July 26, 2013, Activision Blizzard declared its independence.

Blizzard entertainment's record revenue and monthly activity in 2016 were driven by world of warcraft content and overwatch's holiday-themed events. In 2017, Activision Blizzard was expected to generate $\$ 6$ billion in revenue and blizzard entertainment was expected to generate $\$ 2.428$ billion, accounting for 39 percent. In December 2018, world brand lab released the list of the world's top 500 brands 2018, and Activision Blizzard ranked 495 .

\begin{tabular}{|c|c|c|c|}
\hline \multicolumn{4}{|c|}{ TABLE 1. FOURTH QUARTER 2019 SEGMENT } \\
RESULTS
\end{tabular}

\section{ANALYSIS USING SWOT-MODEL}

\subsection{Strength}

Activision Blizzard has a great globe market and 500 million active monthly users around the world. The company's large scale and diversity in geographical aspect can help it to avoid any management risks in a single area. Players can play games of Activision Blizzard by using PC and mobile devices. Besides, Activision Blizzard has a more successful franchise business in revenue scale comparing with EA and Taketwo interactive, which offers unique advantages to Blizzard among video game industry. Furthermore, the products of Activision Blizzard support multiple platforms, including the Sony PlayStation 4, Nintendo Wii, Nintendo Wii U, and Microsoft Xbox 360. Moreover, games developed by Activision Blizzard are also compatible with handheld game systems, including Nintendo Dual Screen and Nintendo 3DS.

\subsection{Weakness}

Sales of gaming consoles generate $34 \%$ of the company's revenue; however, the gaming consoles are managed by 
the third party including Microsoft's Xbox One, and Xbox 360, Nintendo's Wii U, etc. In other words, the company income created through this channel is overly dependent on the circumstance of the third parties; if some unexpected problem happened in platforms running by these companies, Activision Blizzard will be unable to fully recover its investment in developing those products, which may adversely impact its financial position and results of operations. Besides, Activision Blizzard derives significant portion of revenues historically from products based on relatively few popular franchises, these products generate a disproportionate share of profits. Because of this dependence on a limited number of franchises, the company is vulnerable to the performance of these franchises, which may significantly harm business and financial results.

\subsection{Opportunity}

The mobile gaming industry is expected to record strong growth in the coming years. Activision Blizzard is keen to benefit from this growing mobile game market. The company is a worldwide publisher of mobile and tablet games. The robustly growing end market allows the company to expand its market share and revenues in the coming years. Besides, in the past few years, the software market has been growing and is forecasted to continue growing strongly over the forecast period to 2019. Being one of the significant players in the global games software market, Activision Blizzard is well positioned to benefit from the growing end market. Furthermore, Worldwide online gaming market is expected to grow rapidly in the coming years. For example, China is primarily expected to contribute to the majority of the revenue in Asian markets. The company has been increasing its focus on online gaming services in recent years.

\subsection{Threat}

Persistent piracy continues to affect the growth of entertainment players. Unauthorized copying of Activision Blizzard's titles and reverse engineering of the products would enable duplicating of the programming techniques proprietary to the company and creation of similar competitive products. The increasing piracy will adversely affect the business value of Activision Blizzard's products and thereby its revenues. Besides, the interactive entertainment software market is characterized by short product life cycles and frequent introductions of new products. New products introduced by Activision Blizzard may not achieve significant market acceptance or achieve sufficient sales to recover development, manufacturing, and marketing costs. The changes in consumer preferences may have an unfavorable impact on the company's operations and results. Furthermore, Activision Blizzard operates in the highly competitive interactive software industry[4].

The company competes with other publishers of PC and video game console interactive entertainment software. Some of these competitors vary in size from small companies with limited resources to very large corporations with significantly greater financial, marketing and product development resources compared to Activision Blizzard. Intense competition could impact the pricing of the company's solutions. Thus, impacting its margins.

\section{STRATEGY ANALYSIS AND RECMMENDATIONS}

\subsection{Product differentiation strategy}

The first differentiation strategy is product quality differentiation. The product quality strategy of Activision Blizzard is "Boutique strategy", its tour Play development cycle is comparatively longer than other platforms and often delayed releases. This is because Blizzard is very strict about quality control, and defective products must not be released. This strict quality control reflects the "craftsman spirit" in Blizzard culture, and Blizzard enjoys a fundamental worldwide reputation because of this spirit. The products released by Blizzard earned the trust of players because of its particularity and its insignificant cost. The high quality and low price of its products provide advantages to Blizzard in achieving huge sales volume, and the company sold 100,000 copies of games so far. The second difference is the depth and difficulty of the game. A game with a low level of difficulty can make it easy for players to get started and attract many new players in a short time. Deep games allow players to play longer and become loyal users. The last differentiation is game content. Due to the serious imitation and copycat among game producers, the "homogenization" of game content is the most significant problem. Game content refers to the storyline of the game, the background of The Times, and other information. The story backdrops of Blizzard games are all extremely large.

\subsection{Merger and acquisition strategy}

In 2008, the US game video distributor Activision and Blizzard Entertainment merged, and became a new company named Activision Blizzard. After the merger integration, the company's economy and restraint strength are stronger than before, and the company's competitiveness is enhanced. On November 2, 2015, Activision Blizzard acquired the mobile game company King for $\$ 5.9$ billion, and its business scope continued to expand. Patent sharing between companies decreased the costs of research and development costs. In the fierce game industry, the M\&A strategy made the company's market share. Consequently, the proportion of the mobile gaming industry increased.

\section{CONCLUSION}

From the SWOT analysis and forecast calculation data, Blizzard, as one of the largest game companies in North America and the world, has shown a good upward trend in the overall market environment. Activision Blizzard is currently taking a number of measures to cater to the current market. For example, Blizzard is currently investing a lot of resources in the development of popular mobile games. And in the past, it produced a remake of 
world of warcraft, vigorously developed the asia-pacific market, and so on. These measures allow and will allow Activision Blizzard's products to continue to attract attention and take advantage of the huge user base and product system that Blizzard has developed over the years. However, the online game company has a fast industry update and a short development cycle. Under fierce competition, Blizzard's development is also accompanied by danger: relying on third-party platforms, new works are not welcome, and partners have problems. Even so, due to the accumulation of years of operation and the measures to adapt to market changes, it can be predicted that Activision Blizzard's share price will show a steady trend of growth in the coming period of time. Based on the current development of the game industry environment and the same companies in the game industry, Activision Blizzard is an investment option with a steady increase in profits.

\section{ACKNOWLEDGEMENT}

First and foremost, I would like to show my deepest gratitude to my teachers and professors in my university, who have provided me with valuable guidance in every stage of the writing of this thesis. Further, I would like to thank all my friends and roommates for their encouragement and support. Without all their enlightening instruction and impressive kindness, I could not have completed my thesis.

\section{REFERENCES}

1. A. Nusca. Activision Blizzard, Fortune, 2018, p. 92. Available at:

http://search.ebscohost.com/login.aspx?direct=true $\& \mathrm{db}=$ edsgao\&AN=edsgcl.531668295\&lang=zh-cn\&site $=$ eds-live (Accessed: 7 April 2019).

2. Economics Week. Activision Blizzard, Inc. Files SEC Form 8-K, Current Report: Jan. 4, 2019. Available at:

http://search.ebscohost.com/login.aspx?direct=true $\& \mathrm{db}=$ edsbig\&AN=edsbig.A575443957\&lang=zh-cn\&site =eds-live (Accessed: 7 April 2019).

3. T. P. Derdenger. Vertical integration and two -sided market pricing: Evidence from the video game industry. 2009, Available at:

http://search.ebscohost.com/login.aspx?direct=true \&db= cat07017a\&AN=nupc.AAI3389447\&lang=zh-cn\&si te=eds-live (Accessed: 7 April 2019).

4. Activision Blizzard, Inc. SWOT Analysis' Activision Blizzard, Inc. SWOT Analysis, 2019, pp. 1-8. Available at:

http://search.ebscohost.com/login.aspx?direct=true $\& \mathrm{db}=$ bsu\&AN=134890424\&lang=zh-cn\&site=eds-live (Accessed: 7 April 2019). 